\title{
A provocação dos aparatos tecnológicos
}

Celso R. Braida

Universidade Federal de Santa Catarina

\section{Resumo}

A situação humana no mundo dos aparatos maquínicos e das formas tecnológicas de relação e subsistência exige uma revisão da autocompreensão humanista. A tecnologia moderna estabelece uma ruptura com os modos de vida milenares baseados em artefatos pré-científicos, mas isso não implica uma perda ou destruição da essência natural e menos ainda humana. Pois, a existência humana não é antes poética e depois por acidente técnica; e também não é antes carente e indeterminada e por isso técnica, e muito menos prioritariamente desejo natural e então derrelição tecnológica. O humano instaurou-se poética e tecnologicamente ao conformar o mundo pelo uso de artefatos: o seu ter mundo é sempre um perfazer mundo por meio do artifício.

Palavras-chave: Humano; Técnica; Ficção.

\begin{abstract}
The human situation in the world of machinic apparatuses and technological forms of relationship and livelihoods requires a revision of the humanist image. Modern technology provides a break with the ancient ways of life based on pre-scientific artefacts, but this does not imply a loss or destruction of the nature and human essence. Thus, human existence is not before poetic and then by accident technique; and also not before needy and indeterminate and so technical, much less prior natural desire then technological error. The human brought up poetic and technologically and conform the world by the use of artifacts: his have world is always make up the world through fiction.
\end{abstract}

Keywords: Human; Technique; Fiction.

\begin{tabular}{c}
\hline \hline Filosofia e Educação - ISSN 1984-9605 \\
Volume 6, Número 3 - Outubro de 2014
\end{tabular}




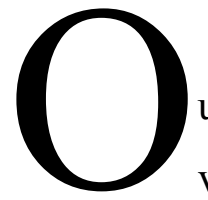

conto The machine stop de E. M. Forster, de 1909, apresenta a utópica situação na qual os humanos são a condição para a vigência da máquina, conquanto vivem como simbiontes que possibilitam a reprodução do sistema maquínico que, tal como as plantas em relação aos insetos, deles dependem para se reproduzir. $\mathrm{O}$ que era então utópico ainda permanece fora de nossa vista; todavia, a atual população humana, nos pontos básicos de sua sociabilidade e relação com o ambiente natural, pode apenas subsistir por meio do uso sistemático e contínuo de artefatos técnicos e sistemas maquínicos: alimentação, acesso à água potável, transporte, comunicação, energia, informação, recreação, saúde, socialização, educação. Os humanos agora dependem do funcionamento contínuo e eficiente de suas próprias criações para viverem do modo como vivem; sistemas maquínicos e ambientes tecnológicos conformam o mundo humano e a formação das novas gerações. A era industrial não completou duzentos anos, e não é menor o seu impacto na cultura hoje, mesmo se já não ouvimos humanos gritarem:

Ah poder exprimir-me todo como um motor se exprime!

Ser completo como uma máquina!

Poder ir na vida triunfante como um automóvel último-modelo!

Esses são versos da Ode Triunfal, de 1914, de Álvaro de Campos, um artifício do poeta Fernando Pessoa. Um século depois o futurismo já não é tão poético, embora os seus cantores estejam por toda parte; apenas as palavras mudaram, pois hoje se ouvem no mesmo tom esperançoso como mantras as palavras "singularidade", "pós-humano", "inteligência artificial", "rede", "complexidade", "informação", "bioinformática". O desejo de ser outro que humano talvez esteja até mais aguçado. Essa atração que nos 
lança em busca das mais ousadas técnicas e tecnologias não é de todo inumana, pois não foi assim que nos alçamos para além da vida animal e dos ciclos naturais?

\section{Hamlet quer ser máquina}

A situação humana no mundo dos aparatos maquínicos e das formas tecnológicas de relação e subsistência foi objeto de consideração por vários pensadores do século passado, entre os quais destacam-se Heidegger, Simondon e Elull. Nas suas considerações sobre a técnica e os sistemas tecnológicos sobressai claramente o fato de que a tecnologia moderna estabelece uma ruptura com os modos de vida milenares baseados em artefatos técnicos pré-científicos. Com efeito, até o surgimento dos relógios, teares mecânicos e moinhos a vapor, os humanos viviam de tal modo que eles mesmos podiam ainda, individualmente ou em grupo, fazerem os instrumentos e apetrechos necessários para manutenção e reprodução da sua vida. Uma diferença produziu-se no momento em que os conhecimentos da nova ciência foram usados para produzir instrumentos e máquinas que, embora sejam meios necessários para as vidas individuais, não são já obras individuais nem estão sob o controle de indivíduos e pequenos grupos, como exemplificam os sistemas de trens e as redes de eletricidade. A ciência moderna, com a ajuda da nova ciência contemporânea, fundada no projeto de uma linguagem formal que apreende todos os eventos como diferenças de informação, expandiu a decodificação dos processos naturais básicos como algoritmos expressáveis e calculáveis. Com efeito, desde a explosão atômica, da descoberta do código genético, da concepção in vitro, dos transplantes, da reprogramação genética, das plantas geneticamente modificadas, da automatização computadorizada e telecomunicações em rede etc, pouco há para se falar em processos naturais indisponíveis ao

Filosofia e Educação - ISSN 1984-9605

Volume 6, Número 3 - Outubro de 2014 
cálculo e à manipulação. Estamos no antropoceno, dizem os sociólogos e biólogos, com isso querendo dizer que estamos na era geológica cujos traços principais são determinados pela ação do homem. Isso porém diz apenas um aspecto, a omnipresença e o predomínio da espécie humana sobre as condições da biosfera. Todavia, o fator principal é o império do artificial alcançado sobre o natural em níveis geológicos. A lógica do fictício e do artifício agora determina e inflete os próprios processos naturais fundantes das condições da vida, atingindo inclusive a própria espécie biológica humana.

A questão da prevalência dos aparatos técnicos, do predomínio das normas e formas tecnológicas de ação e interação, não pode mais ser posta como se uma de suas respostas possíveis fosse o retorno à natureza e à vida provincial. A terra, a flora, a fauna e o artefato, essa série não indica apenas um afastamento da origem telúrica e familiar. Pois, essa série traça um caminho cujo vetor não é reversível. A terra é província, mas o provinciano não é mais capaz de nos satisfazer, pois o retraimento em direção ao natural e ao provincial indicam, como sempre, o caminho de renúncia à humanização. Todavia, a oposição entre naturalização e hipertecnificação é uma falsa imagem do problema, pois o humano se perde por qualquer uma dessas duas vias (Braida, 2011). Nesse ponto a arte já está mais em casa com a nova realidade humana. A peça de Heiner Müller, Hamletmachine, de 1977, serve como sinal dos novos tempos, assim como a peça Pinokio de Roberto Alvim, de 2012: a era na qual o humano é uma condição para aquilo que ele mesmo estabeleceu na terra, o mundo dos humanos em parabiose com objetos técnicos e sistemas cibernéticos.

A técnica e a tecnologia, e sobretudo os seus produtos, as técnicas e dispositivos técnicos, põem, pela sua simples existência, seja da técnica da destilação ou técnica da fertilização in vitro, seja da máquina de debulhar 
milho ou da estação orbital, uma série de questões para a autocompreensão do ser humano e para a compreensão da natureza. Quem somos nós, esses que fazemos máquinas? O que é a natureza, que se deixa moldar como máquina? Não somos nós mesmos efeitos das técnicas de controle e cultura? Não é a natureza mesma um ensaio diante da máquina? Se as técnicas e as máquinas são artefatos, não foi assim que o ocidente se autocompreendeu desde os gregos e cristãos, como artefatos e brinquedos de um deus artesão?

As avaliações filosóficas da situação atual fundam-se em geral na percepção da tecnologia como uma condição determinística, no sentido de que a condição tecnológica se impõe como algo autônomo e fora do controle humano. Haveria uma lógica única e coercitiva por trás da tecnologia induzindo-nos a um futuro incontornável, salvífico para os utópicos, maléfico para os distópicos (Cooper, 2002: 3). O refrão mais recorrente entre os filósofos é negativo: a existência humana estaria, como num quadro de Giger, encarcerada na trama dos sistemas tecnológicos sem possibilidade de escolha e ação fora das possibilidades que esses sistemas estabelecem por sua própria lógica.

Uma abordagem crítica da técnica e da era tecnológica precisa se posicionar como uma recusa de posições que não são opções reais. Para isso é necessário deixar de ver, por um lado, a técnica como um suplemento compensatório para uma carência inautêntica e, por outro, um artifício corruptor da essência humana. A simples oposição dualista entre o bem e o mal, entre vantagem e perigo, é falsa e redutora, pois nem a vida humana nem a natureza e a tecnologia são assim constituídas. O ponto principal da genealogia da técnica consiste em localizar as máquinas e os objetos técnicos no desdobramento contínuo da humanidade, sem pressupor que nisso esteja continuamente atuando uma essência atemporal. A tecnicidade não seria então uma ruptura, mas antes o modo atual de realização humana.

Filosofia e Educação - ISSN 1984-9605

Volume 6, Número 3 - Outubro de 2014 
A partir dessa visada abre-se uma agenda positiva para o pensamento sobre técnica e os aparatos tecnológicos, na qual desaparece a problema da submissão do humano ao maquínico ou da submissão do maquínico ao humano. Nenhuma corrupção ou perda da essência; as máquinas e as tecnologias realizam as possibilidades humanas do mesmo modo que a invenção da escrita no passado realizou e abriu a era espiritual. A letra é tampouco natural quanto a usina atômica e rede mundial de computadores.

Todavia, um raciocínio compreensivo em torno da tecnicidade pervasiva atualmente em curso desvela um aspecto importante, qual seja, o fato de que os indivíduos humanos foram por muito tempo usados para realizar atividades que um mecanismo ou um automatismo pode realizar tão bem ou até de modo mais eficaz. A emergência de objetos técnicos e máquinas inteligentes libera o humano de sua condição prévia de mecanismo de produção. Mas assim liberados, o que fazer? O humano suporta viver sem tarefa?

O fato é que no início desse século as coisas se tornaram mais urgentes, tendo em vista a intromissão pervasiva das tecnologias e dos artefatos inteligentes na vida íntima e nas relações sociopolíticas mais imediatas. A urbanização e a automação do campo, a interligação entre comunicação interpessoal e controle de massas, seja pelas corporações seja pelos governos, determinam um novo nicho ecológico para a pessoa e para as comunidades: não apenas o nosso espaço vital agora é de saída um lugar dentro do espaço artefactual e maquínico, também os espaços mentais e sociais estão em interação e são fundados por ambientes cibernéticos. Esta última predicação é decisiva. Não se trata apenas do fato de que nascemos e morremos no interior de um acontecimento cujo regime é maquínico integralmente (Ellul, 1992), mas também do fato de que pensamos e sentimos em termos computacionais e informacionais. Se a pouco mais de 
100 anos a maior parte da população humana vivia e morria em conformidade com os ciclos naturais, internos e externos, e se defrontava durante toda a sua vida apenas com instrumentos e utensílios cuja serventia podia ser dispensada no principal de seu modo de vida, hoje isso é simplesmente impensável, pois a situação da vida humana agora é de dependência em relação ao ambiente artificial maquínico e de procedimentos e operações computacionais. $\mathrm{O}$ uso de drogas e remédios, o uso da eletricidade e dos meios de transportes, o uso dos computadores e meios de telecomunicações é tal que nossa vida cultural, social e biológica perfaz-se integralmente como figura sobre o fundo constituído por máquinas, procedimentos técnicos e algoritmos. As máquinas e redes inteligentes, contudo, instauram um outro modo ao situarem sua atuação no plano das decisões, pensamentos e desejos, agindo antes e ali mesmo onde o indivíduo e sobretudo os grupos ainda nem sequer são conscientes do que irão escolher e fazer.

Essa situação impõe-se como fato e exige reflexão. Desde o início do século passado muitos pensadores responderam no plano do pensamento ao avanço da técnica e dos regimes maquínicos. Os fatos principais, todavia, eram exteriores ao pensamento, no sentido de que a realidade técnica ainda era concebida sob o paradigma da instrumentalidade e da dominação das forças naturais. A seguir vou mencionar algumas reações principais associadas a Heidegger e a Simondon, com o objetivo de ilustrar os impasses e as ambiguidades dessas respostas. O ponto básico é que a evolução (a natureza) nos conduziu a conceber o universo, o mundo, e a própria natureza, em termos de um senso comum, um esquematismo de objetos, propriedades e relações, que a ciência contemporânea mostra em todas as direções ser um equívoco. A nova imagem do universo, em termos de informação e algoritmos, desfaz, por liquidificação, tanto o mundo dos 
objetos quanto o mundo dos sujeitos individuais, com identidade garantida na própria substância. No mundo tecnológico, e também na imagem do universo quântico, entidades e identidades são apenas momentos fugazes de uma realidade sistêmica e indivisa.

\section{A reação de Heidegger}

A posição de Heidegger na história da formação da filosofia da tecnologia ancora-se na exploração da ambiguidade da ação humana quando ela é mediada por artefatos, pois ela tanto pode ser consistente com a natureza quanto destrutiva. A resolução dessa ambiguidade faz-se pela distinção entre dois ethos, o poético e o explorador, a qual permite Heidegger pensar uma diferença radical entre os aparatos técnicos, como uma ponte e um moinho de vento, e os aparatos tecnológicos, derivados da ciência moderna, como uma hidroelétrica ou um avião. Essa diferença teria a ver com o fato de que as técnicas seriam poéticas e as tecnologias exploratórias em relação à natureza. Um outro aspecto da abordagem de Heidegger consiste na postulação de uma independência da tecnologia em relação à decisão e ação humana. O seu ponto de partida, pode-se dizer, está justamente na recusa de pensar a técnica e a tecnologia como instrumentos do homem, que, por conseguinte, se assim fosse deveriam ser pensados a partir de uma visada antropológica. A tese é ontológica: "sendo desencobrimento da disponibilidade, a técnica moderna não se reduz a um mero fazer do homem" (Heidegger, 2012, p. 22). A isso que conduz o processo, Heidegger denomina "armação" (Ge-stell), a saber, "o apelo de exploração que reúne o homem a dis-por do que se descobre como disponibilidade" (Heidegger, 2012, p. 23)

A visada heideggeriana apreende a técnica a partir do acontecer do ser, e não a partir da história humana. Desse modo ele pode dizer que "como 
modo de desencobrimento a armação é um envio do destino. Destino nesse sentido é também a produção da poiesis." (Heidegger, 2012, p. 27) Os fenômenos da técnica e da tecnologia são submetidos ao conceito de poiesis conquanto indica um produzir (hervorbringen) não limitado ao produzir artístico, e menos ainda ao "poético" e ao técnico-artesanal, mas que inclui a physis, como uma produção desde si (em hautô), como o brotar de uma flor, e a produção artística "desde outro" - en allo. Desde essa apreensão, a técnica antiga é vista como um deixar desabrochar, como um trazer à luz, enfim, como um fazer algo aparecer naquilo que lhe é próprio, ao desencobrir o ser da coisa a partir da própria coisa. A técnica moderna não seria mais poesis; ao contrário, pois teria como característica a produção a partir da armação (Gestell) impositora, tal como se dá exemplarmente no plano inclinado de Galileu. Diferente da técnica antiga, a técnica moderna “explora a natureza", força-a segundo uma lógica que lhe é estranha:

O descobrimento dominante na técnica moderna não se desenvolve , porém, numa produção no sentido de poiesis. O descobrimento que rege a técnica moderna é a exploração que impõe à natureza a pretensão de fornecer energia, capaz de como tal ser beneficiada e armazenada (Heidegger, 2012, p.18-19)

A consideração heideggeriana está determinada em grande parte pela experiência do caráter assombroso e violento da técnica que o europeu vivenciou na primeira metade do século $\mathrm{XX}$, sobretudo pelas duas grandes guerras. A oposição entre duas atitudes poéticas, do dispor (thesei) e do deixar nascer (physei), orienta sua avalização para uma apreensão angustiada da era tecnológica. Se Heidegger percebeu o potencial transformador da tecnologia, ele mais viu seu caráter negativo em relação à 
condição humana. $\mathrm{O}$ avanço da técnica e da ciência como fator preponderante em todas as esferas da vida humana era, naquela época, praticamente um avanço de dominação violenta. Os paradigmas de tecnologia por ele considerados são todos exemplos de disposição e liberação de forças e energias antes bem guardadas pelos ciclos naturais. Ainda são os mitos de Prometeu e de Pandora que ensombrecem os caminhos da floresta negra, o mito da liberação de forças descomunais que ameaçam a vida natural, incluindo a humana.

Todavia, essa apreensão ficou datada depois da transformação da tecnologia e da ciência pela computação digital, pela transformação da sociedade pela informática e pelas tecnologias de controle e estatística. As tecnologias atuais, baseadas no conceito de informação e de programação, bem como o redirecionamento das técnicas pelos conceitos de equilíbrio e autossustentabilidade, se não eliminam os perigos da condição tecnológica, também não estão fundados na exposição de forças descontroladas. Com efeito, na segunda metade do século XX, a tecnologia mostrou-se muito mais frutífera do que destrutiva. Ainda que o caráter de exploração e de desafio em relação às forças naturais continue, o aspecto informacional e de reprogramação emergem como características principais da era tecnológica, a tal ponto que se tornou visível a sua face espiritual. Com efeitos ainda não inteiramente refletidos, Heidegger fez uma análise, típica da fenomenologia, como descrição da essência (ontológica), que elimina de antemão a possibilidade de transformação do ethos da tecnologia e da ciência moderna, portanto, que a fixa no seu estágio inicial como sua essência atemporal. A resposta final de Heidegger (2012, p. 29) está cifrada nessas frases:

Quando o descoberto já não atinge o homem, como objeto, mas exclusivamente como disponibilidade, quando, no domínio do não-

Filosofia e Educação - ISSN 1984-9605

Volume 6, Número 3 - Outubro de 2014 
objeto, o homem se reduz apenas a dispor da disponibilidade - então é que chegou à última beira do precipício, lá onde ele mesmo só se toma por disponibilidade. E é justamente este homem assim ameaçado que se alardeia na figura do senhor da terra. Cresce a aparência de que tudo que nos vem ao encontro só existe à medida que é um feito do homem. Esta aparência faz prosperar uma derradeira ilusão, segundo a qual em toda parte o homem só se encontra consigo mesmo.

Esta resposta supõe uma essência da técnica e uma essência do humano. A ilusão de encontrar-se consigo nos aparatos tecnológicos esconde o perigo da desumanização pela prevalência da tecnicidade:

A ameaça, propriamente dita, já atingiu a essência do homem. O predomínio da im-posição arrasta consigo a possibilidade ameaçadora de se poder vetar ao homem voltar-se para um desencobrimento mais originário e fazer assim a experiência de uma verdade mais inaugural. (Heidegger, 2012, p. 30-1)

Desse modo, não podemos deixar de ver hoje no pensamento de Heidegger as marcas da nostalgia das paisagens bucólicas de um tempo anterior à emergência e predomínio da técnica moderna e suas máquinas de transformação, motores, usinas e fábricas. Em seus textos a imagem da ponte de madeira e do moinho são recorrentes, exatamente nas passagens onde se fala de exploração, de intimação e de forçamento da natureza pelas novas tecnologias. Porém, mesmo que essa diferença de essência entre os objetos técnicos antigos e os produzidos pela técnica moderna fosse real, ainda assim seria questionável a equação heideggeriana pela qual o "humano", o "pensar" e a "poiesis" autênticos estariam em perigo pela 
instauração do mundo baseado na ciência e nas técnicas modernas. $\mathrm{O}$ humano agora estaria diante de um acontecimento para o qual ele não tem defesas, que é a omnipresença da técnica exploradora que tudo dispõe como mera disponibilidade. A única alternativa seria o exercício do "pensar" para além do mero calcular, que Heidegger denominou de pensar meditante (das besinnliche Denken). Esse pensar seria poiesis tal como a techne antiga, na qual estavam conjugadas a atenção à verdade e a atenção ao fluir da própria coisa.

Agora, tem razão Heidegger em nos admoestar a partir dessa oposição? Não estaria ele preso a um esquematismo que opõe de saída arte e técnica, obra poética e artefato técnico, técnica e tecnologia, por pensar a partir do pressuposto naturalista de uma essência do humano, de uma essência da natureza, a qual poderia ser desvirtuada por um acontecimento do ser na sua deriva ontológica? De onde avalia Heidegger para atribuir o valor "perigoso", "violência", "ameaçador" à ciência e à técnica moderna? No cerne da argumentação de Heidegger está a diferença entre uma técnica que explicita as potencialidades de uma coisa ou situação e outra que a transforma e explora a partir das potencialidades de um artefato. Moinho de vento e usina hidroelétrica seriam os exemplos paradigmáticos. Porém, não estaria Heidegger forçando uma oposição ali onde não há nenhuma? $\mathrm{O}$ moinho não transforma a força dos ventos em energia cinética e depois em força mecânica que finalmente desintegra o grão, a madeira, a pedra, etc.? Por acaso o vento não passa agora a ser algo distinto dada a existência do moinho, tal como o rio devido à existência da usina? O vento e o rio não são agora dispostos segundo a lógica do artefato que está preparado para fazer do vento e do rio fontes de energia que não é mais vento nem água tão somente? Por acaso, quando os humanos usaram sinais gráficos para registrar a voz eles não alteraram definitivamente esses sinais e a própria 
visão? Pensar não se transformou em outra coisa ao se deixar inscrever e ler? Não receberam assim uma função que antes não tinham? O letramento não dispõe o pensar e o dizer já como disponíveis?

Com efeito, temos de reconhecer que a técnica antiga e a moderna alteram aquilo que antes era natureza tão somente, e do mesmo modo, fazendo-as matéria-prima e reserva para um artefato que produz algo diferente. Essa é a essência de um artefato, a ficção de uma realidade que não apenas faz as vezes da natural mas também cria novas realidades nãonaturais. A invenção da escrita e a invenção da rede inteligente instauram uma dimensão de realidade e sentido não-natural, e submetem a natureza à sua lógica dispondo-a como matéria-energia - conquanto indicam a presença do humano.

\section{A proposição de Simondon}

A questão da autonomia do fenômeno da técnica é também visível na teorização de Simondon. Todavia, sua perspectiva é diferente. Ao considerar o aspecto de autonomia que se mostra nos objetos técnicos, Simondon sinaliza para a independência em relação aos interesses humanos, mas pensa esse aspecto a partir da lógica interna desses objetos. Na sua análise da técnica, é o processo de concretização convergente que caracteriza a tecnicidade. Na base da concretização de um objeto técnico individual, como um motor à combustão, ocorre um processo evolutivo caracterizado pela unificação de suas partes e funções em um todo orientado pelas necessidades de sintonia e acoplamento (Simondon, 1989, p. 19, 54).

Visto a partir do seu desenvolvimento e concretização, a forma atual de um objeto técnico individual é uma resultante de necessidades internas. Falamos então de "descobertas", de modificações "necessárias para o aperfeiçoamento" da máquina. E do ponto de vista da operação, nós mesmos 
somos executores passivos, e sobretudo adaptamo-nos ao funcionamento e características das máquinas. Os humanos fabricam os instrumentos e artefatos tecnológicos para obterem os resultados desejados, sem dúvida, mas a questão é que nem eles nem os seus desejos permanecem inalterados no percurso de desenvolvimento e concretização dos objetos técnicos. À primeira vista, esses objetos parecem ser apenas meios empregados para afinar a relação entre o homem e a natureza; todavia, já os primeiros artefatos e técnicas alteraram os termos da relação, no sentido de que tanto o elemento humano quanto o artefato e a natureza não permaneceram sendo o que eram. E esta alteração se dá justamente pelo fato de que a introdução de um instrumento ou técnica altera a situação e a condição humana. Por isso, na abordagem de Simondon, o objeto técnico não é apenas um mediador entre humano e natureza, constituindo antes uma totalidade híbrida cujas partes e funções são inseparáveis em que se conjugam "humano" e "natureza": "um misto estável de humano e natural; ele dá a seu conteúdo humano uma estrutura semelhante à dos objetos naturais, e permite a inserção, no mundo das causas e efeitos naturais, desta realidade humana" (Simondon, 1989, p. 245). A inserção de artefatos e técnicas, já nos seus primeiros estágios, instaura uma nova dimensão ontológica, pois "uma convertibilidade do humano em natural e do natural em humano institui-se por meio do esquematismo técnico" (Simondon, 1989, p. 245).

Simondon percebe que essa situação constitui um novo patamar de individuação, pois propriamente o objeto técnico distingue-se das entidades individuais típicas, físicas e biológicas. O objeto técnico é "o suporte e o símbolo da transindividualidade", uma vez que é por meio do objeto técnico que uma relação inter-humana se estabelece. Trata-se de uma relação (relation) que não põe os indivíduos em ligação (rapport) por meio de sua individualidade constituída, separando-os uns dos outros, nem por meio do 
que há de idêntico em todo sujeito humano, $[. .$.$] mas por meio dessa carga$ realidade pré-individual que é conservada com o ser individual, e que contêm potenciais e virtualidade (Simondon, 1989, p. 247). Nesse sentido, os objetos técnicos, e mais ainda os sistemas tecnológicos atuais, estabelecem formas de ser transindividuais que implicam uma união entre o humano e o maquínico, portanto, um regime transumano. Simondon (1989, p. 09) é claro quanto a esse ponto:

A oposição sustentada entre a cultura e a técnica, entre o homem e máquina, é falsa e sem fundamento; ela esconde ignorância e ressentimento. Por trás de um humanismo fácil, ela mascara uma realidade rica em esforços humanos e em forças naturais, e que constitui o mundo dos objetos técnicos, mediadores entre a natureza e o homem.

A compreensão da técnica e da tecnologia desdobrada por Simondon é, de saída, pró-ativa ao evitar o negativismo e as falsas oposições entre humano e técnica, ou entre técnica e natureza. A chave para essa compreensão está na abordagem genético-genealógica, a qual ao invés da atitude pessimista e saudosista, pensa a situação do mundo permeado pela técnica sem tomá-lo como o decaimento do homem e da natureza nem como a emergência de uma realidade utópica e ideal. Uma das preocupações centrais de Simondon é com a educação humana justamente para liberá-lo da falsa escolha entre ser escravo ou senhor da máquina.

L'humanisme doit viser à libérer ce monde des objets techniques qui sont appelés à devenir médiateurs de la relation de l'homme au monde. [...] La relation de l'homme au monde et de l'individu à la communauté passe par la machine. [...] Entre la communauté et

Filosofia e Educação - ISSN 1984-9605

Volume 6, Número 3 - Outubro de 2014 
l'individu isolé sur lui-même, il y a la machine, et cette machine est ouverte sur le monde. Elle va au-delà de la réalité communautaire pour instituer la relation avec la Nature (Simondon, 2005, p. 527).

O que ele propõe, afinal, é uma genealogia das relações homemmundo que apreenda os objetos técnicos e as tecnologias como uma forma de se fazer mundo. A técnica insere-se no contínuo da deriva da cultura como modo de dar sentido e significado à experiência, conquanto ela também é um modo de interação homem e mundo, humano e natureza. Nesse sentido, Simondon aborda a educação tecnológica como estando no mesmo patamar de sentido humano que o mito, a religião, a arte, a ciência e a ética. O saber tecnológico insere-se no contínuo da cultura que constitui a "natureza" humana, pois ali onde há o humano, há artefatos e técnicas, e a tecnologia não rompe com essa correlação, mas sim a reitera e realiza.

\section{O império da técnica}

A situação humana na vida condicionada pelas tecnologias, na forma de sistemas maquínicos e cibernéticos, mas também nas tecnologias sociais e educacionais, emerge como propriamente inumana. Se em Heidegger e Simondon a consideração ainda era de advertência ao homem para que ele não se perdesse sob os artefatos tecnológicos, nas considerações de J. Ellul e de Teixeira ouve-se claramente a nota do pós-humano como o futuro da sociedade tecnológica:

O mundo pós-evolutivo não será nem melhor nem pior do que o atual. O desenvolvimento da tecnologia parece ser nossa única saída para sobreviver à involução. A parabiose, ou seja, nossa mistura com as máquinas, não é um aperfeiçoamento artificial da espécie

Filosofia e Educação - ISSN 1984-9605

Volume 6, Número 3 - Outubro de 2014 
humana, mas sim uma de suas últimas tentativas de sobreviver. (Teixeira, 2010, p. 154)

O ponto de partida para a reflexão é justamente o da autonomia da técnica. Para Ellul (1969, p. 129), a "civilização técnica” indica à primeira vista uma forma de vida humana, mas essa expressão também indica a submissão do humano aos regimes maquínicos, no sentido de que ela está “construída para a técnica (tudo o que está nessa civilização deve servir a um fim técnico)" e que ela "é exclusivamente técnica (exclui tudo o que não o é ou reduz a sua forma técnica)". O humano sucumbe ao ordenamento técnico que ele criou:

A vitória atual é do utensílio; e somente o utensílio que tem o poder e que detém a vitória. [...] O homem obedece e não tem mais vitória que lhe seja própria. Não pode aliás ter acesso a esses aparentes triunfos a não ser tornando-se ele próprio objeto da técnica, tornando-se produto do acoplamento entre a máquina e o homem. (Ellul, 1969, p. 149)

A fusão humano-máquina, enquanto configura o mundo atual e faz infletir os destinos da própria biosfera é o que se denomina antropoceno. A espécie humana, ao construir seu meio ambiente por meio do estabelecimento de aparatos maquínicos e da introdução de produtos sintéticos, se impõe agora como o principal fator determinante da vida ou morte das demais espécies e, talvez, dos ciclos geológicos. Todavia, ao se erigir sobre os sistemas tecnológicos os humanos a cada novo ciclo de expansão adaptam-se às necessidades dos objetos técnicos e dos sistemas maquínicos. Por conseguinte,

\begin{tabular}{c}
\hline \hline Filosofia e Educação - ISSN 1984-9605 \\
Volume 6, Número 3 - Outubro de 2014
\end{tabular}


A técnica não tem mais [...] freio algum em sua marcha; não encontra mais obstáculo; pode avançar à vontade, não tendo outro limite senão o das suas próprias forças. Ora, essas forças parecem inesgotáveis e ilimitadas. O fato de uma técnica sem limites, no entanto, não é em si mesmo inquietante. É preciso admitir afinal de contas que nossa sociedade é técnica. O que nos parece mais impressionante, porém, é que esse caráter da técnica a torna independente do próprio homem. (Ellul, 1969: 311)

Ellul não é um defensor da ideia de pós-humanidade, contudo. A sua tese é de que a espécie humana está em processo de tornar-se voluntariamente dependente dos sistemas tecnológicos e dos aparatos maquínicos, na exata medida que estes eliminam sua dependência em relação à natureza. Por isso, seu diagnóstico incide sobre o risco de perda de autonomia do humano em relação à ordem maquínica e tecnológica:

Não se trata mais, então, de fazer desaparecer o homem, mas de levá-lo à composição, de levá-lo a enquadrar-se na técnica, a deixar de experimentar os sentimentos e as reações que lhe seriam pessoais. Não há técnica possível com um homem livre. Pois, quando a técnica penetra em todos os domínios da vida social, choca constantemente o homem, na medida em que o funcionamento da técnica deve necessariamente chegar a determinado resultado. (Ellul, 1969, p. 140)

Todavia, esse diagnóstico negativo sobre a situação humana na era tecnológica não pode ser mantido sob pena de se reconhecer na técnica uma potência extra-humana. Ellul fala de um "poder dotado de força própria" p. 143. que se sobrepõe ao "poder” humano de controlá-lo. Ellul (1969, p. 146) 
parte, sem dúvida, de um diagnóstico correto:

Nada mais é do domínio dos deuses, dos poderes não naturais. $\mathrm{O}$ homem vive no meio técnico sabe bem que não há mais nada espiritual em parte alguma. E, no entanto, assistimos a uma estranha reviravolta; o homem não pode viver sem o sagrado; transfere seu senso do sagrado para aquilo mesmo que destrói tudo o que era seu objeto (do sagrado): para a técnica. No mundo em que vivemos foi a técnica que se tornou o mistério essencial.

Prosseguindo assim no aprofundamento da visão negativa típica do século XX. Todavia, justamente esta consequência, que a vida humana autêntica está em perigo pela omnipresença da técnica, supõe que o humano configurado historicamente até o início do século XIX era o humano autêntico segundo sua essência. Esta suposição não tem nenhum cabimento nem fundamento. A elisão dessa crença nos libera para pensar o acontecer e o evoluir das técnicas e tecnologias, dos objetos técnicos e dos sistemas tecnológicos, como um acontecimento espiritual exatamente no mesmo sentido que a passagem do humano caçador-coletor para o humano agricultor o foi, ou a passagem da língua para a escrita.

Uma consideração lúcida sobre a situação humana atual tem de admitir que em todas as relações fundamentais e em todos os aspectos da vida as mediações tecnológicas estão presentes como condição que altera e impõe não apenas esses fundamentos como os próprios relatas. Ainda assim, essa consideração não pode cair na ilusão de que essas mediações tecnológicas sejam algo cuja deriva nada tem a ver com a orientação principal da espécie humana. Contudo, é certo que atualmente essa espécie biológica subsiste como dominante frente às outras apenas enquanto está em 
parabiose com os artefatos tecnológicos. Sob uma visão panorâmica sobre a atual situação da biosfera terrestre são bem marcantes as transformações em curso, tanto nas condições vitais gerais quanto na sobrevivência e extinção de espécies, decorrentes da introdução de produtos e de modificações em nível mineral, orgânico e ecossistêmico, propiciados pela ciência e pela tecnologia modernas. Essas transformações têm origem na ação de grupos e indivíduos da espécie humana. Mas, também é evidente o fato de que essa espécie agora depende para se manter, nos atuais níveis populacionais e vitais, do uso sistemático e contínuo de instrumentos, máquinas e procedimentos tecnológicos. A condição artefactual é tal que a cultura do artificial e do tecnológico é percebida como uma condição urgente.

\section{A genealogia do artifício}

A linguagem, e sobretudo a linguagem escrita, estão entre os mais antigos artefatos a ganharem independência em relação aos indivíduos e grupos humanos. Uma língua e um alfabeto, desde os seus começos eram já artefatos cuja lógica interna submetia os indivíduos de modo cogente e incontornável; também uma constituição e uma organização de instituições, como os primeiros impérios se apresentavam como algo maior e independente do homem. A concretização plena de uma língua e de uma técnica de escrita é hoje tida como um acontecimento da maior importância na conformação do humano, exatamente por alterar a própria autocompreensão de si e estabelecer relações antes impossíveis, fazendo assim emergir um novo plano de realidade na qual tanto o grupo quanto os indivíduos humanos, nas suas relações consigo e com o meio ambiente, não são mais os mesmos de antes. A projeção de uma explicação não-natural e não-humana desse acontecimento é recorrente, ao se atribuir aos deuses, ao se ver nesses artefatos o dom divino.

Filosofia e Educação - ISSN 1984-9605

Volume 6, Número 3 - Outubro de 2014 
A técnica moderna aparece como diferente justamente pela ausência de uma justificação transcendente, mais ainda, pela própria impossibilidade de ser projetada como natural ou divina, restando apenas a ação humana como sua fonte. $\mathrm{O}$ que era o homem submetido ao império do estado ou da igreja, senão escravo e mão de obra? Não exercia ele as funções sob a mesma exigência que agora fazemos a uma máquina? A precisão no cumprimento das ordens e promessas, a infalibilidade nas tarefas, o rigor na disciplina religiosa e militar, a organização e a projeção de metas; o exército, a igreja, o estado, não eram já aparatos artificiais cuja racionalidade ideal agora foi transferida para instrumentos e dispositivos?

A grande diferença está no fato que nos últimos cem anos o único vetor de melhoramento e sustentação da condição humana consiste nas novas tecnologias e novas máquinas (Winner, 1989, p. 5). Aparatos, plantas e animais modificados, circuítos eletrônicos, bioengenharia, etc.: as sociedades agora jogam todas as suas fichas na ciência e na tecnologia como forma de progresso e de melhoramento das condições de vida. Os adoradores e os detratores da técnica, mesmo quando fazem uma reflexão erudita, ao sacralizarem a técnica como um acontecimento ontológico e até mesmo teológico, obnubilam os fatores humanos que dirigem o inteiro processo. As técnicas e tecnologias são formas de realização da espécie humana e, por isso, tem de ser consideradas como modos de atuação da nossa espécie. Já se disse que ao humano é natural o uso de artefatos, e esse aspecto agora precisa ser repensado sob a tese de que a atual fase tecnológica da humanidade não é nenhuma ruptura com a essência do humano e também não com a natureza.

Nesse aspecto é que as investigações de Simondon são relevantes, pois ele dispensou a ideia de que a técnica seja algo independente do homem, mas também que o homem seja independente da técnica: tanto o 
homem quanto a técnica são sem-essência, no sentido de serem intrinsecamente constituídos histórica e relacionalmente. Isso significa abordar as técnicas e os objetos técnicos sem pressupor que eles sempre tiveram e têm hoje a mesma função, a mesma finalidade, a mesma posição, enfim, o mesmo sentido. A abordagem genealógica está justamente nessa disciplina. Em diferentes culturas, os objetos técnicos têm diferentes status, pois sua natureza é relacional.

Ao sugerir que na sua forma atual, na sociedade tecno-industrial, os artefatos e aparatos finalmente aparecem na sua essência funcional e instrumental pura, diz-se que alcançamos a essência e a finalidade metafísica da técnica e dos artefatos técnicos. Ora, isso é uma perspectiva muito curta, pois não deixa ver o quanto de valor e sentido não-instrumental estão investidos nos nossos artefatos técnicos, ao mesmo tempo que se sugere assim uma continuidade de essência que anularia as transformações reais. Um automóvel, um telefone celular, um vestuário, um complexo industrial, não existem na forma e na posição em que existem em uma sociedade apenas porque são instrumentos, pois a própria instrumentação é explicada em termos não-instrumentais. Embora se possa falar da instrumentalidade (ou do caráter funcional) dos objetos técnicos, esse aspecto nunca é ele mesmo puro e capaz de explicar a presença e sobretudo a forma e o sentido de sua complexidade interna e menos ainda de seu propósito dentro da cultura. A análise de Pierre Clastres, do papel configurador do cesto e do arco na cultura Guayaki ${ }^{1}$ ilustra esse ponto: o

${ }^{1}$ Clastres, 2003, "O arco e o cesto", p. 117-143: "Podemos então medir o valor e o alcance da oposição socioeconômica entre homens e mulheres porque ela estrutura o tempo e o espaço dos Guayaki. Ora, eles não deixam no impensado o vivido dessa práxis: têm uma consciência clara e o desequilíbrio das relações econômicas entre os caçadores e suas esposas se exprime, no pensamento dos índios, como a oposição entre o arco e o cesto. Cada um desses dois instrumentos é, com efeito, o meio, o signo e o resumo de dois "estilos" de existência tanto opostos como cuidadosamente separados" (p. 123); "A dura lei dos Guayaki não lhe deixa alternativas. Os homens só existem como caçadores, e eles mantêm a certeza de seu ser preservando o seu arco do contato da mulher. Inversamente, se

Filosofia e Educação - ISSN 1984-9605

Volume 6, Número 3 - Outubro de 2014 
cesto e o arco são sim instrumentos, objetos técnicos, talvez os mais sofisticados dessa cultura, mas a sua função e a sua posição dentro da economia semântica não se esgota nem se explica apenas por essa função tecno-instrumental. Neles também está inscrito a própria norma pela qual os seus artesões se autoconfiguram como humanos. No caso das ditas civilizações industrializadas, isto é, marcadas profundamente pelos sistemas tecnológicos, a relação entre certos objetos técnicos e a forma de sociabilidade pode não ser tão direta, mas não é menos premente. Nessas sociedades, a evolução de um objeto técnico e de uma tecnologia é caracterizada por rupturas, retomadas, reinterpretações e reapropriações, nas quais nem a forma nem o sentido permanecem intactos. A descrição disso que aí está em dada situação não é capaz de explicar como isso veio a ser, e a descrição da história de formação não explica o sentido e a função atuais; além disso, a descrição das relações objetivas de um objeto técnico com outros objetos ainda não nos diz nada sobre a sua história de formação, e esta história não explica a sua posição na autoconfiguração humana. Por isso, a abordagem genealógica, tal como proposta por Nietzsche, e em parte aplicada por Simondon, mostra-se melhor preparada do que a abordagem fenomenológica na tarefa de compreensão do lugar e do papel dos objetos técnicos. Neles não opera uma essência, nem o vigor de um destino, mas sim exercita-se um agenciamento semovente que se apropria do que quer que seja com vistas ao empoderamento e à autoconstituição.

Kojève (1979) esboçou a figura do esnobe japonês como o máximo da artificialidade; embora isso seja um equívoco histórico, a tese assim exemplificada tornou-se um dos refrões mais repetidos e repensados. A

um indivíduo não consegue mais se realizar como caçador, ele deixa ao mesmo tempo de ser um homem: passando do arco para o cesto, metaforicamente ele se torna uma mulher. Com efeito, a conjunção do homem e do arco não se pode romper sem transformar-se no seu inverso e complementar: aquela da mulher e do cesto.” (p. 125)

Filosofia e Educação - ISSN 1984-9605

Volume 6, Número 3 - Outubro de 2014 
tecnologia e as técnicas constituem o humano em qualquer momento de sua história, por isso não há como colocar esse aspecto como a fonte da deshistoricização do homem. Da perspectiva aberta por Hegel, e seguida por Kojève e Agamben (2002, p. 16-20), a dissolução do Humano com o fim da história é o seu tornar-se animal outra vez, o voltar a se integrar à natureza. Noutra perspectiva, Heidegger manteve e exasperou a separação entre animal e humano, mas pensou o humano em termos bucólicos, como pastor da physis e do ser. A partir de Nietzsche, a dissolução não é outra coisa que o desmoronamento de um artifício idealista-cristão que, ao se realizar como visão de mundo científica moderna, abriu a possibilidade da emergência, não do animal-natureza recalcado e esquecido, mas de outras possibilidades de espiritualização e artificialização. O übermenschlich não é um animal ou um não-animal, mas um além outro da realização do espírito da terra, que, nesse devir, não retorna à sua essência de outrora, mas sim realiza sua potência que é sempre possibilidade de outridade.

O devir animal do humano, na leitura de Kojève do texto hegeliano, já continha a nota da consciência infeliz, que indica que o fim da história não torna o homem feliz, mas isso também se aplica ao devir-artefato do humano. Não está em questão a felicidade ou a realização do humano na forma que ele pensa que é e se projeta, mas a experiência do além-de-si do homem fixado pela história passada, delineado pela técnica da escrita e das leis ético-políticas, conquanto este agora se realiza como máquina inteligente-espiritual. O que se realiza assim ainda é humano, mas apenas em parte confirma a auto-imagem delineada nos últimos cinco mil anos; pois, em parte também realiza algo que tem de ser nomeado apropriadamente de inumano. 


\section{Um ambiente artefactual}

O mundo dos artefatos, por mais complexa que seja a rede de conexões e acoplamentos, determina-se pela forma de vida humana e suas necessidades. Todavia, esse fato, de que o humano agora é condição para a existência de algo, constitui o problema principal, pois se antes a inteira natureza era colocada como condição para a história e a formação do humano, agora a existência humana parece estar em função de sua própria criação, os artefatos tecnológicos.

Ainda assim, as estruturas e as funções, portanto o sentido, dos artefatos e sistemas tecnológicos, apenas podem ser compreendidos a partir dos interesses e necessidades da população humana. Essa condição fornece a racional da tecnologia, até mesmo quando o humano aparece como apenas uma parte ou um traço interno aos sistemas maquínicos: uma espécie que reduz seu metabolismo para se adequar a um nicho adverso de modo a sobreviver e se expandir. A lógica da expansão tecnológica e do aumento de aparatos maquínicos no ambiente humano representa uma atuação da espécie e dos indivíduos homo sapiens em nada diferente das atuações evolutivas transformadoras de outras espécies.

O ambiente artefactual, contudo, é propriamente o mundo constrangido pela atitude teorética cujo cerne está na prévia apreensão do que se dá sempre como objeto manipulável. A atitude teorética que dispõe tudo o que é experienciado como objeto ainda não é a atitude tecnológica. Esta emerge quando os objetos mesmos são constituídos a partir de uma visada que os apreende enquanto potencialmente "argumentos" e "funções", isto é, uma apreensão objetiva funcional. A partir dessa apreensão a queda d'água fragmenta-se em "queda" e "água", e então transforma-se ou em fornecedora potencial de água a uma certa distância, ou em fornecedora de energia, ou em reserva hídrica, ou em lago artificial para criação artificial de 
peixes ou para recreação etc. A queda ou água, ou ambas conjuntamente, agora são dados como argumentos de uma função cujo resultado é determinado exclusivamente pela função.

As posições de Heidegger e de Simondon podem ser sumarizadas como apreensões diante do poder do artificial. Se Heidegger reclama para si o pensar meditante capaz de subsumir o pensamento que conduz o fenômeno da técnica moderna sob a rubrica do perigo e da perda da essência do homem, Simondon não é menos arqueológico ao exibir positivamente o fato de que apenas educando-se tecnologicamente o homem pode estar a altura da autonomia dos objeto técnicos. No início desse século, todavia, essas posições são inviáveis para quem quer continuar pensando. Não é apenas o fato de que os exemplares de tecnologia, tomados por Heidegger e Simondon como paradigmáticos, terem sido ultrapassados pelos novos artefatos maquínicos. Embora possamos sempre adicionar mais e mais exemplos que mostrariam os limites daqueles exemplares, o que importa é sobretudo a atitude teórica, isto é, o ethos da apreensão, que tem de ser abandonado, pois nela subjaz uma dicotomia metafísica, a qual, por seus princípios, instaura como linha de inteligibilidade a baliza da separação entre real e irreal, autêntico e inautêntico, fato e essência, poiesis e exploração.

A retórica da integralidade, que opõe a conservação do natural e do tradicional, característicos da técnica antiga, à exploração e ao desafio da natureza, inerentes à técnica moderna, permanece cativa da compreensão do ato de Galileu, ao submeter os corpos ao plano inclinado, como uma ofensa e submissão da natureza aos planos da razão. Em dois pontos essa compreensão da ciência e da técnica dela derivada está ultrapassada. Primeiro, ela não mais é capaz de apreender a própria transformação da ciência moderna a partir de Newton, Darwin, Mendel, e sobretudo as teorias 
do século $\mathrm{XX}$, pois a concepção de natureza e de teoria são muito diversas da de Galileu; segundo, a separação entre realidade fisical e realidade orgânica desaparece a partir das teorizações da termodinâmica e da química contemporânea. As entidades naturais, na perspectiva da ciência atual, não são essências imutáveis e isoladas na sua identidade, que, por meio de um acontecimento qualquer, ontológico ou prático, poderiam ser desintegradas. Apenas quem fixou a vida humana e a natureza, digamos, na forma de uma pequena aldeia no alto Reno em meados do século XV, como configuração poética da existência, pode pensar uma usina hidroelétrica e um motor a combustão como ruptura destrutiva e como perigo irreversível.

A técnica $\mathrm{e}$ as tecnologias não são o perigo, nem ameaçam a essência do homem, pois não se põe essa questão, visto o homem ser inseparável do artefactual. Justamente ao homem não cabe a diferença entre poético e explorador, pois essa oposição mesma supõe a vigência de uma vida que não é mais natural, pois, na sua base estão atos e fatos poéticodisposicionais que supõe a natureza como sendo sempre já disponível para transformações e derivas. Em outras palavras, "natureza" e "condição humana" não são termos naturais ou essências que ao se alterarem por atos de ficção perderiam sua integralidade. Esses termos indicam antes fixações habituais de uma forma de vida que estabilizou sua situação como ideal e eterna. Os objetos técnicos antigos e os sistemas tecnológicos contemporâneos não são uma afronta à natureza e ao ser (essência), mas sim seu desdobramento e realização. Nem a natureza nem o humano se perdem, por exemplo, nas técnicas de modificação genética na medicina e no uso de aparatos cibernéticos na educação e na socialização das crianças; pois, o que aí estava e que agora é transformado foi também o resultado imprevisível de alterações e rupturas a partir do que antes existia como natural. No sentido mesmo da ideia de educação está a ideia de desenvolver o que aí está em 
tensão com a ideia de instaurar através de artifícios algo diferente. No gesto de recusa que quer afastar o tecnológico, ao pensá-lo como contrário ao espírito, também se pode ver o desprezo pela educação em nome de alguma essência inaudível.

Uma resposta à altura que constitua uma projeção de futuro tem de recusar de saída a separação entre objetos técnicos e objetos artísticos, entre arte e tecnologia, pois ela que relega a vigência da técnica ao não-espiritual e ao inumano. Recuperar a unidade entre ars et scientia, enquanto realizações e concreções do espírito, é o único caminho que preserva aquilo que constitui os humanos como humanos e ao mesmo tempo abre a possibilidade de um uso criativo da tecnologia. Do mesmo modo que Husserl podia dizer que a atitude teorética cria uma postura humana que imediatamente engrena em toda a restante vida prática, com todas as suas exigências e fins, os fins dessa tradição histórica no interior da qual se foi educado e de onde retiram a sua validade, a atitude tecnológica perfaz o mundo e a educação sob os quais formam-se os humanos atuais. Essa atitude quer ser universal, tal como a atitude teorética, mas diferente desta, quer dispor o próprio mundo nos seus termos, isto é, requer-se também como prática. Por isso, a comunidade tecnológica não é mais apenas humana; o termo apropriado seria "trans-humana", pois o próprio elemento humano é, tal como o dado histórico e o dado natural, agenciado como um objeto que vale enquanto argumento no interior do ambiente funcional. $\mathrm{O}$ liame dessa comunidade, diferente da palavra franca na assembleia, é a palavra cifrada dos códigos de máquina e linguagens artificiais.

A separação, no plano da essência, proposta por Heidegger, entre arte e técnica, e entre a antiga poiesis e a produção tecnológica, acentua a fenda que exclui a mentalidade tecnocientífica das mais altas balizas do espírito, as quais são deixadas apenas com os artistas. Essa separação não é 
essencial nem necessária, e muito menos um destino, mas sim um autoengano herdado da compreensão não-naturalista do espírito. Uma vez eliminado o engano dessa cisão, as manifestações artísticas e tecnológicas passam a ser vistas como uma apresentação indivisa da mesma potência pela qual o humano se autoinstaurou como espírito frente a natureza. Recusar umas em favor das outras, como o fez Heidegger, ao aproximar a arte do fluir natural, é não perceber que tanto os artefatos técnicos quanto os artefatos artísticos são fatores constituintes da natureza genealógicoperformativa do humano.

Nesse sentido, a proposta de Simondon continua válida, qual seja, a de que a educação das novas gerações inclua a educação para a convivência, nem servil nem dominadora, com os objetos técnicos. Apenas faz-se necessário acrescentar que uma educação para a dimensão espiritual inclui a educação artística. Por isso, uma nova educação, baseada na fusão entre arte e tecnologia, enquanto ambas são as concreções do espírito, é a única alternativa capaz de evitar tanto a catástrofe que seria o império da exploração e da dominância tecnocrática quanto a derrocada do espírito que seria o retrocesso ao liame naturalista.

A conjunção de modos de decisão, instituições, hábitos, normatização, conformação do desejo e da imaginação, do discurso científico e das artes, das perspectivas de futuro e da própria vida individual e coletiva, na forma de aparatos tecnológicos que se interligam em sistemas de acoplamento e sincronização, perfaz o mundo atual como uma máquina que, embora ainda não absoluta, retira suas forças não mais da relação imediata com os ciclos da biosfera, mas sim de algoritmos e mecanismos, conformando assim uma existência maquínica na qual o humano tanto se instaura quanto se conforma. O sentido e a forma da vida humana agora está indissociavelmente ligado à configuração do espaço vital pela lógica dos 
sistemas tecnológicos. Nesse espaço estão os germes da nova face humana e as indicações da nova educação para uma atitude transumana. Sem dúvida, sempre poderemos recuar para estágios anteriores ou nos fixarmos em figuras passadas do espírito. Todavia, o cerne da espiritualidade sempre esteve associada à semovência antes que ao apego ao passado. Ainda assim, sem assombro, a nossa hora exige uma espiritualidade lúcida que recuse tanto o canto sedutor da renaturalização quanto às tentações da vida maquínica. O humano agora precisa recuar de sua soberania irrefletida sobre a natureza, sobretudo quando ela se explicita como construção de máquinas inteligentes, o que não significa de modo algum o retorno à vida bucólica pré-moderna.

\section{Nada perdeu a poesia}

Uma constante no discurso negativo e alarmista diante do caráter pervasivo dos sistemas tecnológicos é o refrão da perda da arte e da poesia, estas associadas intrinsecamente à vida espiritual. $\mathrm{O}$ avanço das técnicas e tecnologias na configuração da vida humana implicaria o perigo da perda da dimensão poética. Contudo, essa apreensão é claramente uma ilusão, tanto em relação ao poético quanto em relação ao espírito. Com efeito, em todas as passagens para atitudes transformadoras, houve poetas que cantaram o "antes do fim" tanto quanto o "depois do fim", e nenhum foi menos poeta ou menos espiritual. Fernando Pessoa era lúcido quanto a isso:

Nada perdeu a poesia. E agora há a mais as máquinas

Com a sua poesia também, e todo o novo gênero de vida Comercial, mundana, intelectual, sentimental,

Que a era das máquinas veio trazer para as almas.

(Ode Triunfal)

Filosofia e Educação - ISSN 1984-9605

Volume 6, Número 3 - Outubro de 2014 
Os defensores dos "velhos bons tempos" podem sempre fazer a pose do Velho do Restelo ${ }^{2}$ e amaldiçoar os "novos tempos", porém o fato é que eles mesmos educaram as gerações para esse desejo e para essa forma de mundo. Essa réplica, todavia, é inexata, pois nenhuma geração passada conseguiu evitar o futuro que as colocaria como ultrapassadas. Nesse sentido, a era tecnológica, configurada que é pelos aparatos e sistemas maquínicos, impõe-se como se fosse um destino e não uma escolha do homem político ou religioso. Da natureza biológica nós nos afastamos a muito tempo. Esse afastamento não foi também uma decisão, mas ainda assim também não foi um destino, mas uma escolha reiterada por milênios e milênios a cada vez que um grupo um indivíduo optava por uma regra arbitrária contrária à deriva natural. Ao agir assim por reiteração do artifício, o espírito humano alcançou a fase de sua existência na qual seu gesto se quer não-biológico e não-orgânico. Esse espírito agora configura-se espelhando-se na figura da retocável perfeição maquínica. Assim provocados, nós temos a oportunidade de rever a secular violência contra a natureza em nós e fora de nós pela qual nós nos configuramos. Diante de uma máquina inteligente, não podemos não ver isso que se mostra como aquilo que as mais das vezes e seguidamente gostaríamos de ser, mas também de perceber o quanto a natureza ainda vive através de nosso espírito cultivado.

Nada perdeu a poesia, nada perdeu a humanidade na era dos aparatos tecnológicos. As minhas considerações, se não compactuam com a tese de que a era tecnológica significa a perda da essência humana e natural, também não se unem àqueles que enxergam na técnica e na tecnologia o complemento superador da suposta carência natural do humano. Ao evitar

\footnotetext{
${ }^{2}$ Personagem d'Os Lusíadas, de Camões (canto IV, estâncias 94-104). (N. do Ed.)
} 
conceber a tecnologia seja como perda, seja como complemento, o que se evita é pensá-la como um acontecimento exterior à realização do espírito. Artefatos, técnicas e sistemas tecnológicos são expressões e expansões do espírito do mesmo modo que arte o é. Não tanto a necessidade, a carência, enfim, a finitude, está na origem das técnicas e tecnologias, mas antes aquele impulso que quer ir além da vida e da natureza enquanto elas não bastam, como disse Pessoa sobre a arte e a literatura. Ao recusá-las, a técnica e a tecnologia, recusa-se o espírito do mesmo modo que com a renegação da arte. $\mathrm{O}$ visado é uma posição que não mistifique o acontecimento, e mantenha desassombrada frente ao perigo e à sedução da absolutização dos sistemas tecnológicos. O humano habita poética e tecnologicamente o mundo: o seu ter mundo é sempre um perfazer mundo por meio do artifício.

A existência humana não é antes poética e depois técnica; e também não é antes carente e indeterminada e por isso técnica, e muito menos prioritariamente desejo e então tecnológica. Os artefatos, técnicas e tecnologias abrem o mundo humano, e a atitude poética emerge em sua plenitude apenas quando assume essa abertura. Nesse ponto o filme de Tarkowski, Stalker, continua sendo uma imagem mais acurada da condição humana. O cientista e o artista, ambos apostam nos favores da abertura, apenas aquele que é capaz de os conduzir até lá, ali se orientar e voltar para casa não pode gozar nem da viagem nem da experiência. A figura basal do espírito humano é a do stalker, embora sejam o engenheiro e o escritor os que pareçam melhor apresentá-la de modo completo. Uma reviravolta em direção à naturalização do humano não está à vista nem é desejável, pois isso significaria um desabrigo do espírito. Mas disso não se segue que o humano não possa se projetar como uma forma de existência póstecnológica, no sentido de uma vida humana que, se não se submete aos 
aparatos técnicos, também não se reduz aos ciclos naturais, justamente por emergir poeticamente com base e para além dos aparatos tecnológicos.

\section{Referências}

AGAMBEN, Giorgio. L'Aperto: L'uomo e l'animale. Torino, Bollati Boringhieri, 2002 .

BRAIDA, C. R. ((2013). "A falsa opção entre renaturalização e hipertecnificação”. Filosofia Unisinos 14 (1): 70-83.

CLASTRES, Pierre. A sociedade contra o estado. São Paulo, Cosac \& Naify, 2003.

COOPER, S. Technoculture and Critical Theory: In the service of the machine? London, Routledge, 2002.

ELLUL, Jacques. A técnica e o desafio do século, Rio de Janeiro, Paz e Terra, 1969. “"Technology and Democracy", em WINNER, 1992, pp. 35-50.

FORSTER, E. M. “A máquina para”; trad. C. R. Braida, (n.t.), n.2, (2011): 248279.

HEIDEGGER, Martin. Escritos e conferências. Petrópolis, Vozes, 2012.

KOJÈVE, Alexandre. Introduction à la lecture de Hegel. Paris, Galimard, 1979.

PESSOA, Fernando. Ficções de Interlúdio / 4: Poesias de Álvaro de Campos. Rio de Janeiro, Nova Fronteira, 1983.

SIMONDON, Gilbert. Du mode d'existence des objets techniques. Paris: Aubier, 1989.

L'individuation à la lumière des notions de forme et information. Paris, Ed. Jérôme Millon, 2005.

TEIXEIRA, João de Fernandes. A mente pós-evolutiva: a filosofia da mente no universo do silício. Petrópolis, Vozes, 2010.

WINNER, Langdon. The whale and the reactor: a search for limits in an age of high technology. Chicago, Chicago University Press, 1989. . Democracy in a technological society. Dordrecht, Springer, 1992. 